\title{
Assessment of the effect of horseshoes with and without traction adaptations on the gait kinetics of nonlame horses during a trot on a concrete runway
}

\author{
Pengju Wang BVM, MS \\ Catherine Takawira MSC \\ Takashi Taguchi DVM, MS \\ Xiao Niu BVM \\ Munir D. Nazzal PhD \\ Mandi J. Lopez DVM, PhD
}

Received June II, 2020.

Accepted August 17, 2020.

From the Department of Veterinary Clinical Sciences, School of Veterinary Medicine, Louisiana State University, Baton Rouge, LA 70803 (Wang, Takawira, Taguchi, Niu, Lopez); and Department of Civil and Architectural Engineering and Construction Management, College of Engineering and Applied Science, University of Cincinnati, Cincinnati, $\mathrm{OH} 4522$ I (Nazzal).

Address correspondence to Dr. Lopez (mlopez@lsu. edu).

\begin{abstract}
OBJECTIVE
To assess the effect of horseshoes with and without traction adaptations on the gait kinetics of nonlame horses during a trot on a concrete runway.

ANIMALS

5 nonlame adult light-breed horses.

\section{PROCEDURES}

Kinetic data were obtained for each horse when it was trotted across a force platform within a concrete runway unshod (control) and shod with standard horseshoes; standard horseshoes with high profile-low surface area calks, with low profile-high surface area calks, and coated with a thin layer of tungsten carbide (TLTC); and plastic-steel composite (PSC) horseshoes. Kinetic data were obtained for the control treatment first, then for each of the 5 shoe types, which were applied to each horse in a random order. Kinetic variables were compared among the 6 treatments.
\end{abstract}

\section{RESULTS}

Body weight distribution did not differ among the 6 treatments. Compared with the control, the greatest increase in forelimb peak vertical force was observed when horses were shod with PSC shoes. In the hind limbs, the greatest increase in peak braking force was observed when horses were shod with PSC shoes, followed by the TLTC and low profile-high surface area calked shoes. The PSC shoes yielded the greatest coefficient of friction in both the forelimbs and hind limbs. Stance time was longest when horses were shod with standard shoes.

\section{CONCLUSIONS AND CLINICAL RELEVANCE}

Results suggested that PSC and TLTC shoes provided the best hoof protection and traction and might be good options for horses that spend a large amount of time traversing paved surfaces. (Am J Vet Res 2021;82:292-30I)
$\mathrm{H}$ orseshoes are frequently modified to enhance traction for horses that travel on paved surfaces for work, pleasure, or entertainment. ${ }^{1-4}$ The types of equids that travel on paved surfaces range from draft horses to ponies, and the use of those animals varies from a basic means of transportation in Amish communities 5 to police service horses ${ }^{6}$ and tourist wagon and buggy rides. ${ }^{3,7}$ Information is available about the effect of horseshoe modifications such as toe grabs and studs on traction and other gait kinetics for horses used for racing and pulling, but little is known

$\begin{array}{ll}\text { ABBREVIATIONS } \\ \text { COF } & \text { Coefficient of friction } \\ \text { GRF } & \text { Ground reaction force } \\ \text { HC } & \text { High profile-low surface area calk } \\ \text { IMP } & \text { Braking impulse } \\ \text { IMP }_{P} & \text { Propulsion impulse } \\ \text { IMP } & \text { Vertical impulse } \\ \text { LC } & \text { Low profile-high surface area calk } \\ \text { PBF } & \text { Peak braking force } \\ \text { PPF } & \text { Peak propulsion force } \\ \text { PSC } & \text { Plastic-steel composite } \\ \text { PVF } & \text { Peak vertical force } \\ \text { TLTC } & \text { Thin layer of tungsten carbide }\end{array}$

about the kinetic effects of other common horseshoe modifications used to enhance traction, such as calks, tungsten carbide granules, or plastic composites. ${ }^{8-10}$ That information is vital for horseshoe design to enhance traction on pavement and prevent slipping and to protect the safety and welfare of service, working, and leisure horses.

Calks are elevations of forge-welded metal that are typically added to the toe and heel portions of a horseshoe on the side that comes into contact with the ground surface (road surface). ${ }^{11}$ They are frequently composed of tungsten carbide, an exceptionally hard and durable metal. ${ }^{12}$ Calks can have a high or low profile. ${ }^{11}$ Hard metal calks, especially those with a high profile, damage paved roads because of stress concentration. 5 To reduce road damage and enhance traction for the horse, 2 horseshoe modifications have been developed: the application of TLTC granules to the entire road surface of the shoe and a custom shoe composed of a steel frame embedded in a compressible plastic component., 13 To date, objective data regarding the effects of those shoe adaptations on hoof traction are limited. Direct compari- 
sons among distinct horseshoe modifications or configurations are warranted to identify adaptations that best enhance traction with minimal gait alterations.

Determination of GRFs by use of a force platform is an established method for quantifying hoof traction and weight-bearing in horses. ${ }^{14,15}$ Ground reaction forces are measured in 3 planes (vertical $[\mathrm{Z}]$, mediolateral $[\mathrm{X}]$, and craniocaudal $[\mathrm{Y}]$ ) that intersect at a single point in the center of a force platform. ${ }^{16}$ For any given limb, the peak force is the maximum force measured during stance in each of the 3 planes. Peak vertical forces are used to assess weight-bearing in limbs, frequently before and after systemic or local treatments, and the $\mathrm{PVF}_{\mathrm{Z}}$ s typically increase when the limbs are protected from hard ground surfaces by horseshoes. ${ }^{17,18}$ Forces measured over time are impulses, or areas under the force-time curves on each axis. ${ }^{19}$ Craniocaudal forces are divided into braking and propulsion phases. Braking begins to increase at initial impact of the hoof with the force platform or ground surface and accounts for approximately $60 \%$ and $40 \%$ of the total stance time for the forelimbs and hind limbs, respectively. ${ }^{20}$ Slipping usually occurs during braking. ${ }^{21}$ The COF is the dimensionless ratio of braking to vertical GRF that corresponds to the friction between the hoof and ground surface 22,23 ; the COF increases (ie, has a greater negative value) as traction increases. ${ }^{21,24}$ Collectively, GRFs and associated measures provide valuable metrics for assessing the effect of distinct horseshoe configurations on limb weight-bearing and traction in horses.

Horseshoe material, road surface roughness, and the contact area between the horseshoe and ground surface affect the COF. ${ }^{25-28}$ Lateral heel studs and toe grabs significantly increase the COF and reduce hoof slipping in horses ${ }^{10,24}$; however, toe grabs reportedly increase the risk of suspensory apparatus strain and failure from toe elevation on hard surfaces. ${ }^{8,29}$ The use of calks to provide traction for horses that travel on hard surfaces creates a level platform for the hoof, potentially limiting abnormal hoof placement, but COF data for metal calks on hard surfaces are lacking. ${ }^{5}$ Because the COF decreases as contact stress increases, ${ }^{30}$ horseshoes with calks may have a lower COF than standard horseshoes, and that difference may increase as the calk contact surface area decreases. The COF increases with surface roughness; therefore, the addition of a TLTC to the road surface of a shoe might improve traction. ${ }^{28}$ Horseshoes composed of compressible plastic might have a greater COF than horseshoes composed of metal owing to both material properties and an increase in contact surface area. ${ }^{31,32}$

The purpose of the study reported here was to assess the effect of horseshoes with and without traction adaptations on the gait kinetics of nonlame horses during a trot on a concrete runway. For both forelimbs and hind limbs of 5 nonlame horses, the respective percentage changes in $\mathrm{PVF}_{\mathrm{Z}}$ and $\mathrm{PBF}$ were evaluated between the unshod state and when the horse was shod with standard horseshoes or horseshoes with a TLTC on the road surface, with HCs, with LCs, or composed of a PSC. Our hypotheses were that, compared with the unshod state, the $\mathrm{PVF}_{Z}$ would increase similarly in shod horses across all shoe types; the PBF when horses were shod with TLTC or PSC shoes would be greater than when horses were unshod or shod with standard shoes; the PBF when horses were shod with TLTC, PSC, and standard shoes would be greater than when horses were shod with LC and HC shoes; and the PBF when horses were shod with LC shoes would be greater than when horses were shod with HC shoes in both the forelimbs and hind limbs. Our overarching goal for this research was to establish baseline information to guide horseshoe designs that promote the safety of horses that routinely traverse paved surfaces while minimizing damage to paved surfaces, which endangers public safety and increases maintenance costs.

\section{Materials and Methods}

\section{Animals}

All animal procedures were reviewed and approved by the Louisiana State University Institutional Animal Care and Use Committee (protocol No. 18129). Prior to study initiation, a power analysis and sample size calculation ${ }^{\text {a }}$ were performed. Given the mean \pm SD GRF data reported in a previous study ${ }^{1}$ and assuming a significance level of $5 \%(\alpha=0.05)$ and power of $80 \%(\beta=0.20)$, it was determined that a minimum of 5 horses would need to be evaluated for the planned analyses.

Five horses were selected from a research herd for study enrollment. To be included in the study, each horse had to be a mare or gelding of a light horse breed between 10 and 25 years old with no evidence of clinical illness or lameness, a body condition score between 4 and 7 on a 10-point scale, and body weight between 400 and $600 \mathrm{~kg}$. Horses were individually housed in stalls $(3.6 \times 3.6 \mathrm{~m})$ with concrete floors covered by rubber mats beginning 5 days before initiation of data collection and throughout the observation period. Each horse had free access to water, which was provided in a 16-L bucket and refreshed at least twice daily, and was fed $2.7 \mathrm{~kg}$ of a commercial horse feed ${ }^{\mathrm{b}}$ and $4 \mathrm{~kg}$ of Bermuda grass hay twice daily.

\section{Study design}

The study had a 6-way crossover design with approximately 22 hours between treatments. For each horse, a comprehensive physical examination and lameness evaluation were performed before study initiation, prior to force platform testing for each treatment, and at the conclusion of the study. A professional farrier trimmed the hooves of each horse, and approximately 5 days later, each horse underwent force platform testing for collection of kinetic gait data while it was unshod. Subsequently, for each 
horse, the order in which each of the 5 types of horseshoes was applied was determined in a random manner by means of a random number generator. The same type of horseshoe was applied to all 4 feet of each horse during each treatment, and all horseshoes were applied by a professional farrier. Approximately 22 hours after each shoe type was applied, each horse underwent force platform testing for collection of kinetic gait data. Immediately after completion of data collection, the horseshoes were replaced by the next designated shoe type and the process was repeated until kinetic data had been collected for all 5 shoe types. Following completion of kinetic gait data collection for all 6 treatments (unshod and shod with standard, HC, LC, TLTC, and PSC shoes), standard radiographic views were obtained of all 4 feet of each horse to assess for radiographic evidence of damage to the hoof capsule and phalanges.

\section{Horseshoe design and application}

A commercially available iron horseshoe ${ }^{c}$ was used without modification (standard shoe) or served as the base for application of calks or a TLTC. The HC shoes were modified by the placement of 3 calks at the toe portion and 1 calk at each heel portion of the shoe (ie, 5 calks/shoe). Each calk applied to the HC shoes had a height of $10 \mathrm{~mm}$ and diameter of $10 \mathrm{~mm}$. Three calks were equidistantly spaced along the toe portion of the shoe, with the central calk positioned at the point of the shoe. The distance between the center of the central calk and the center of the calk on either side of it was approximately $20 \mathrm{~mm}$. The calk at each heel portion was positioned approximately 10 $\mathrm{mm}$ from the palmar or plantar edge of the shoe (Figure I). The LC shoes were modified by the placement of 1 calk at the toe portion and 1 calk at each heel portion of the shoe (ie, 3 calks/shoe). For each LC shoe, the calk applied at the toe portion had a height of $5 \mathrm{~mm}$, length of $40 \mathrm{~mm}$, and width of $20 \mathrm{~mm}$ and was contoured to the shape of the toe of the shoe. The calks applied at the heel portion had a height of $5 \mathrm{~mm}$, length of $20 \mathrm{~mm}$, and width of $20 \mathrm{~mm}$, and the center of each heel calk was positioned approximately $20 \mathrm{~mm}$ from the palmar or plantar edge of the shoe. The TLTC shoes had TLTC granules (granule diameter, 1 to $3 \mathrm{~mm}$ ) applied over the entire road surface of the shoe. The PSC shoes ${ }^{\mathrm{d}}$ were commercially available and composed of a steel frame embedded in compressible plastic. The shoe covered the entire surface of the sole except for an open window over the frog and each sulcus. The hoof side of the PSC shoe had 15 rounded plastic elevations (diameter, $2 \mathrm{~mm}$; height, $3 \mathrm{~mm})$ and a metal clip $(20 \times 20 \times 5 \mathrm{~mm})$ at each quarter. The road surface of the PSC shoe had 2 treads $(30 \times 40 \times 20 \mathrm{~mm})$ at each quarter. Each shoe was affixed to a hoof with 2 No. 5 horseshoe nails ${ }^{\mathrm{e}}$ on each side, and the nail holes in the hoof wall were reused as much as possible to minimize tissue damage. The contact surface area and weight of each type of shoe were summarized (Appendix).

\section{Kinetic gait data collection}

Kinetic gait data collection was performed in accordance with a previously described protocol. ${ }^{33-35}$ Ground reaction forces were measured with a force platform $^{\mathrm{f}}$ (dimensions, $900 \times 900 \mathrm{~mm}$ ) that was embedded in the center of a 40-m-long concrete runway. The surface of the force platform was the same color and texture as the runway. The horses were conditioned to trot across the force platform prior to data collection, and experienced handlers trotted all horses for all conditioning and experimental trials. A trial was defined as 1 pass over the runway and force platform. A trial was considered successful if a horse's forelimb and then the ipsilateral hind limb contacted the force platform while the animal was trotting at a velocity of 2.0 to $4.0 \mathrm{~m} / \mathrm{s}$ with an acceleration of -1.0 to $1.0 \mathrm{~m} / \mathrm{s}^{2}$. A trial was declared unsuccessful and was excluded from analysis if a horse's hoof did not land in its entirety on, was not straight on, or was within $5 \mathrm{~cm}$ of the edge of the force platform. Trial velocity and acceleration were determined with a series of 5 retroreflective photocell sensors. ${ }^{g}$ Automated data recording was triggered by the detection of a force $\geq$ $50 \mathrm{~N}$ on the force platform. All trials were recorded at a rate of $1,000 \mathrm{~Hz}$ and subsequently processed with commercially available software. ${ }^{\mathrm{h}}$ The entire data collection system, force platform, and photocell sensors were calibrated prior to each test session. For each horse and treatment (shoe) combination, a minimum of 5 successful trials were recorded for the left and right limbs.

\section{Radiographic evaluation}

Following collection of all kinetic gait data, all horseshoes were removed and each horse was sedated with xylazine ${ }^{\mathrm{i}}(0.5 \mathrm{mg} / \mathrm{kg})$ and butorphanol $\mathrm{i}^{\mathrm{j}}(0.1$ $\mathrm{mg} / \mathrm{kg}$ ) combined in the same syringe and injected into a jugular vein. Standard lateromedial radiographic images of all 4 feet were obtained approximately 15 minutes later. Briefly, radiographic images of each unshod hoof were obtained with the horse standing on wooden blocks with the $\mathrm{x}$-ray beam ${ }^{\mathrm{k}}$ centered on the hoof from a distance of approximately $0.3 \mathrm{~m}$. All radiographs were evaluated for bone, joint, and hoof capsule changes by a board-certified large animal surgeon (MJL).

\section{Statistical analysis}

Gait variables evaluated included $\mathrm{PVF}_{\mathrm{Z}}, \mathrm{IMP}_{\mathrm{Z}}, \mathrm{PBF}$, $\mathrm{IMP}_{\mathrm{B}}, \mathrm{PPF}, \mathrm{IMP}_{\mathrm{P}}$, stance time, braking time, propulsion time, body weight distribution, and COF. All forces were normalized on the basis of horse body weight, which was measured on a digital scale. ${ }^{1}$ For each horseshoe type, the percentage change in $\mathrm{PVF}_{\mathrm{Z}}, \mathrm{IMP}_{\mathrm{Z}}, \mathrm{PBF}$, $\mathrm{IMP}_{\mathrm{B}}, \mathrm{PPF}, \mathrm{IMP}_{\mathrm{P}}$, and stance time relative to the unshod state (control) was calculated separately for the forelimbs and hind limbs as follows: ([mean forelimb or hind limb value when shod - mean forelimb or hind limb value when unshod]/[mean forelimb or hind limb value when unshod]) $X 100$, where the mean val- 

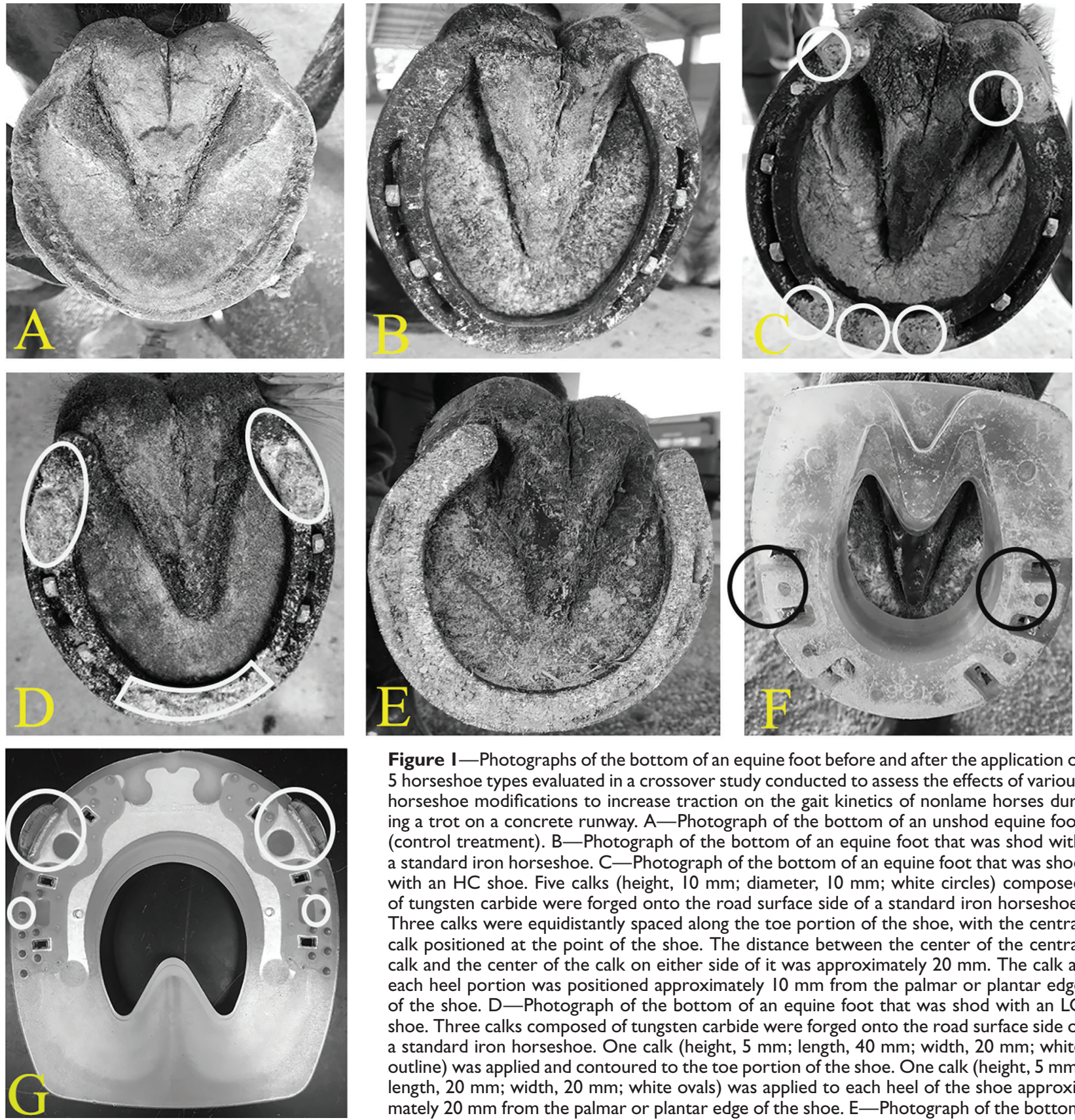

Figure I-Photographs of the bottom of an equine foot before and after the application of 5 horseshoe types evaluated in a crossover study conducted to assess the effects of various horseshoe modifications to increase traction on the gait kinetics of nonlame horses during a trot on a concrete runway. A-Photograph of the bottom of an unshod equine foot (control treatment). B-Photograph of the bottom of an equine foot that was shod with a standard iron horseshoe. C-Photograph of the bottom of an equine foot that was shod with an $\mathrm{HC}$ shoe. Five calks (height, $10 \mathrm{~mm}$; diameter, $10 \mathrm{~mm}$; white circles) composed of tungsten carbide were forged onto the road surface side of a standard iron horseshoe. Three calks were equidistantly spaced along the toe portion of the shoe, with the central calk positioned at the point of the shoe. The distance between the center of the central calk and the center of the calk on either side of it was approximately $20 \mathrm{~mm}$. The calk at each heel portion was positioned approximately $10 \mathrm{~mm}$ from the palmar or plantar edge of the shoe. D-Photograph of the bottom of an equine foot that was shod with an LC shoe. Three calks composed of tungsten carbide were forged onto the road surface side of a standard iron horseshoe. One calk (height, $5 \mathrm{~mm}$; length, $40 \mathrm{~mm}$; width, $20 \mathrm{~mm}$; white outline) was applied and contoured to the toe portion of the shoe. One calk (height, $5 \mathrm{~mm}$; length, $20 \mathrm{~mm}$; width, $20 \mathrm{~mm}$; white ovals) was applied to each heel of the shoe approximately $20 \mathrm{~mm}$ from the palmar or plantar edge of the shoe. E-Photograph of the bottom of an equine foot that was shod with a TLTC shoe. A TLTC granules (diameter, I to $3 \mathrm{~mm}$ ) was applied to the road surface of a standard iron horseshoe. F-Photograph of the road surface of a PSC shoe applied to the bottom of an equine foot. Two treads $(30 \times 40 \times 20$ $\mathrm{mm}$; black circles) were present at each quarter of the shoe. G-Photograph of the hoof side of a commercially available PSC shoe, which was composed of a steel frame embedded in compressible plastic. The shoe covered the entire surface of the sole except for an open window over the frog and each sulcus. The hoof side of the PSC shoe had I5 rounded plastic elevations (diameter, $2 \mathrm{~mm}$; height, $3 \mathrm{~mm}$; small white circles) and a metal clip ( $20 \mathrm{X}$ $20 \times 5 \mathrm{~mm}$; large white circles) at each quarter. Each shoe was affixed to a hoof with 2 No. 5 horseshoe nails on each side, and the nail holes in the hoof wall were reused as much as possible to minimize tissue damage.

ue when shod or unshod was the mi for the parameter of interest from 10 successful trials (5 successful tria analyzed for each foreli hind limb for each treatment [horseshoe type combination]).

The percentage of body weight distribution for the forelimbs and hind limbs of each horse when unshod and when shod with each shoe type was calculated as follows: ([sum of $\mathrm{PVF}_{\mathrm{Z}}$ from both forelimbs or hind limbs]/[sum of $\mathrm{PVF}_{Z}$ from all 4 limbs]) $X 100$.

For each shoe type, the percentage change in body weight distribution for the forelimbs and hind limbs of each horse when shod, compared with when

the horse was unshod, was calculated as follows: ([forelimb or hind limb percentage body weight distribution for the shoe type of interest - forelimb or hind limb percentage body weight distribution when unshod]/[forelimb or hind limb percentage body weight distribution when unshod]) $X 100$. 

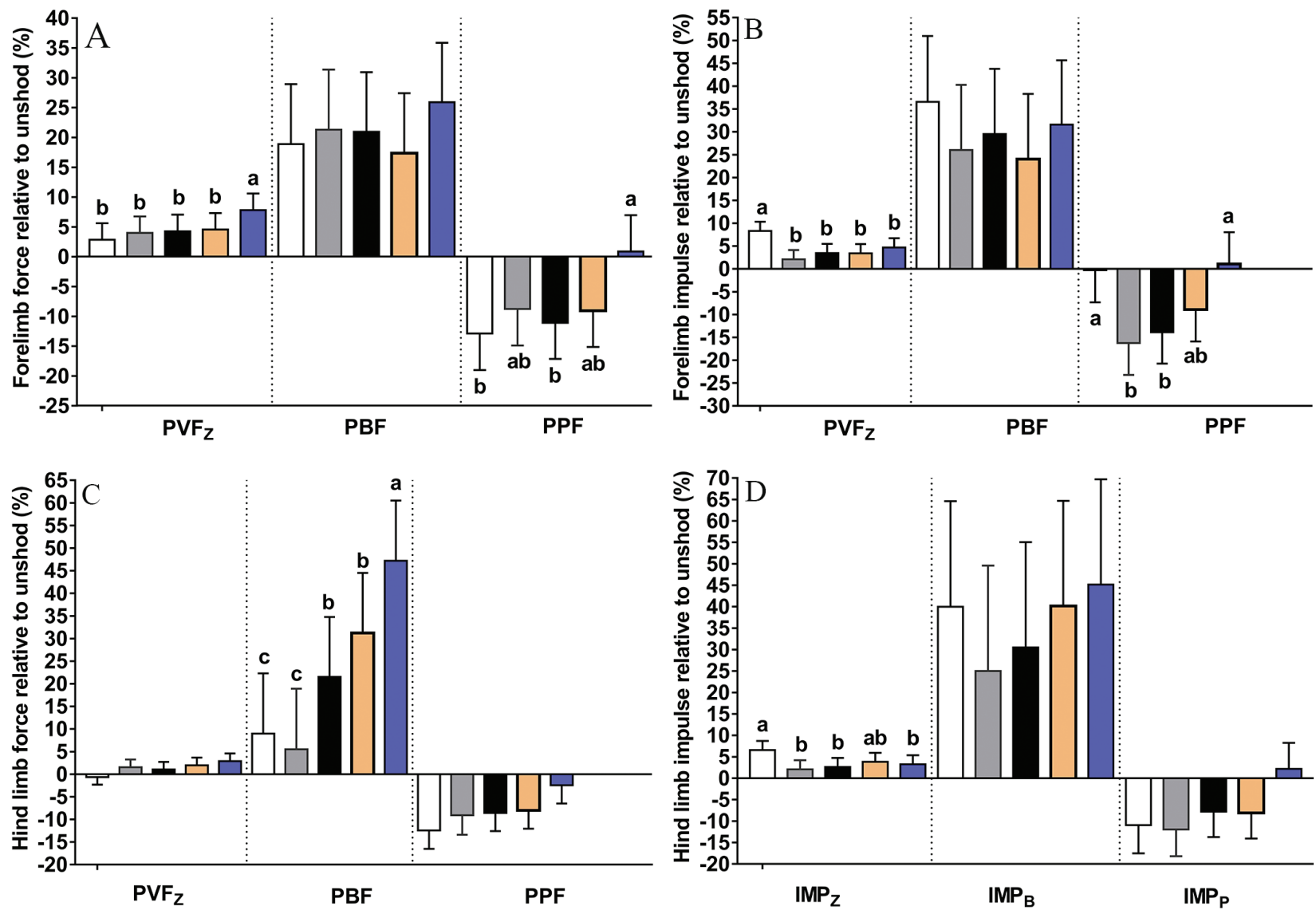

Figure 2-Least squares mean \pm SEM percentage change in $\mathrm{PVF}_{\mathrm{Z}}, \mathrm{PBF}$, and $\mathrm{PPF}(\mathrm{A}$ and $\mathrm{C})$ and $I M \mathrm{P}_{\mathrm{Z}}, \mathrm{IMP}_{\mathrm{B}}$, and IMP $(B$ and $\mathrm{D})$ for the forelimbs (A and $B$ ) and hind limbs ( $C$ and $D)$ of 5 adult nonlame light-breed horses when they were shod with the standard (white bars), HC (gray bars), LC (black bars), TLTC (tan bars), and PSC (blue bars) shoes described in Figure I relative to when they were unshod. Each shoe type (treatment) was applied to each horse in a random order with approximately 22 hours between treatments. Within a variable, values (bars) with different lowercase letters differ significantly $(P \leq 0.05)$.

For each of the 6 treatments, the COF was calculated as $\mathrm{PBF} / \mathrm{PVF}_{\mathrm{Z}}$.

A commercially available statistical software program $^{\mathrm{m}}$ was used to compare trial velocity among the 6 treatments by means of a repeated-measures 1-way ANOVA with the Greenhouse-Geisser correction used for post hoc pairwise comparisons when necessary. Another commercially available statistical software program $^{\mathrm{n}}$ was used to assess the effect of treatment on each gait variable by means of mixed model analyses. Each mixed model included a fixed effect for treatment and a random effect for horse to account for repeated measures within horses. The Tukey honest significant difference test method was used when post hoc pairwise comparisons were warranted. For all analyses, values of $P \leq 0.05$ were considered significant.

\section{Results}

\section{Horses}

The 5 horses enrolled in the study included 4 American Quarter Horse geldings and 1 Tennessee Walking Horse mare. The study population had a mean \pm SEM age of $16.4 \pm 2.2$ years and body weight of $499.0 \pm 36.7 \mathrm{~kg}$.

\section{Kinetic gait analysis}

Compared with when the horses were unshod (control), the mean percentage increase in forelimb $\mathrm{PVF}_{\mathrm{Z}}$ was greatest for the PSC shoes. In fact, the mean percentage increase in forelimb $\mathrm{PVF}_{\mathrm{Z}}$ for the PSC shoes was significantly greater than that for the other 4 shoe types, and the mean percentage increase in forelimb $\mathrm{PVF}_{\mathrm{Z}}$ did not differ significantly among the HC, LC, TLTC, and standard shoes (Figure 2). The mean percentage change in forelimb PPF was positive for the PSC shoes (ie, the mean PPF when horses were shod with PSC shoes was greater than when horses were unshod) and negative for the other 4 shoe types (ie, the mean PPF when horses were shod with each of those 4 shoe types was less than when horses were unshod). The mean percentage change in forelimb $\mathrm{IMP}_{\mathrm{Z}}$ was greatest for standard shoes and did not differ significantly among the other 4 shoe types. The mean percentage change in forelimb $\mathrm{IMP}_{\mathrm{P}}$ for the PSC shoes was significantly greater than that for the HC and LC shoes. The mean percentage change in hind limb PBF for the PSC shoes was significantly greater than that for the other 4 shoe types. The mean percentage change in hind limb PBF did not differ significantly between the TLTC and LC 
shoes or between the standard and HC shoes and was significantly greater for the TLTC and LC shoes, compared with that for the standard and HC shoes. The mean percentage change in hind limb $\mathrm{IMP}_{\mathrm{Z}}$ for the standard shoes was significantly greater than that for the HC, LC, and PSC shoes.

The mean trial velocity and acceleration did not differ significantly among the 6 treatments (Table I). Compared with the control treatment, the mean percentage change in stance time was greatest for the standard shoes for both the forelimbs and hind limbs (Figure 3). The mean percentage change in body weight distribution did not differ significantly among the 5 shoe types for either the forelimbs or hind limbs. For the forelimbs, the mean COF was least for the control treatment and did not differ significantly among the 5 shoe types. For the hind limbs, the mean COF was greatest for the PSC shoes followed by the TLTC and LC shoes and least for the control treatment and standard shoes. The mean braking time was lon- gest for the standard shoes and shortest for the control treatment in both the forelimbs and hind limbs. For the forelimbs, the mean propulsion time for the HC shoes was significantly shorter than that for the control treatment but did not differ significantly from the mean propulsion time for the other 4 shoe types. The mean propulsion time did not differ significantly among the 6 treatments for the hind limbs.

\section{Radiographic findings}

None of the horses had abnormal radiographic findings identified in the hoof capsule or distal phalanges of any foot.

\section{Discussion}

When horses traverse paved surfaces, hoof protection and traction are vital to the welfare of the animals as well as the people riding or driving them. In the present study, the $\mathrm{PVF}_{\mathrm{Z}}$ for the forelimbs was increased when the horses were shod, compared with

Table I-Least squares mean \pm SEM values for COF, braking time, propulsion time, velocity, and acceleration as determined from data collected during force plate testing for the forelimbs and hind limbs of 5 adult nonlame light-breed horses when they were unshod and shod with standard, HC, LC, TLTC, and PSC horseshoes.

\begin{tabular}{|c|c|c|c|c|c|c|}
\hline Shoe type & Limb & COF & $\begin{array}{l}\text { Braking time } \\
(\mathrm{ms})\end{array}$ & $\begin{array}{c}\text { Propulsion time } \\
\text { (ms) }\end{array}$ & $\begin{array}{c}\text { Velocity } \\
(\mathrm{m} / \mathrm{s})\end{array}$ & $\begin{array}{c}\text { Acceleration } \\
\left(\mathrm{m} / \mathrm{s}^{2}\right)\end{array}$ \\
\hline $\begin{array}{l}\text { Unshod } \\
\text { Standard } \\
\text { HC } \\
\text { LC } \\
\text { TLTC }\end{array}$ & $\begin{array}{l}\text { Forelimb } \\
\text { Forelimb } \\
\text { Forelimb } \\
\text { Forelimb } \\
\text { Forelimb }\end{array}$ & $\begin{array}{l}-0.096 \pm 0.004^{a} \\
-0.107 \pm 0.004^{b} \\
-0.108 \pm 0.004^{b} \\
-0.106 \pm 0.004^{b} \\
-0.103 \pm 0.004^{a, b}\end{array}$ & $\begin{array}{l}208.4 \pm 11.2^{\mathrm{a}} \\
237.6 \pm 11.5^{\mathrm{b}} \\
224.1 \pm 11.4^{\mathrm{a}, \mathrm{b}} \\
227.2 \pm 11.3^{\mathrm{a}, \mathrm{b}} \\
224.3 \pm 11.3^{\mathrm{a}, \mathrm{b}}\end{array}$ & $\begin{array}{r}109.8 \pm 13.3^{\mathrm{a}} \\
105.8 \pm 13.3^{\mathrm{a}, \mathrm{b}} \\
87.7 \pm 13.4^{\mathrm{b}} \\
93.8 \pm 13.3^{\mathrm{a}, \mathrm{b}} \\
96.9 \pm 13.3^{\mathrm{a}, \mathrm{b}}\end{array}$ & $\begin{array}{l}2.98 \pm 0.03 \\
2.80 \pm 0.05 \\
3.10 \pm 0.05 \\
2.98 \pm 0.08 \\
2.94 \pm 0.10\end{array}$ & $\begin{array}{r}0.11 \pm 0.07 \\
-0.21 \pm 0.19 \\
0.53 \pm 0.26 \\
0.04 \pm 0.07 \\
-0.06 \pm 0.09\end{array}$ \\
\hline PSC & Forelimb & $-0.108 \pm 0.004^{b}$ & $220.6 \pm 11.2^{\mathrm{a}, \mathrm{b}}$ & $100.2 \pm 13.3^{\mathrm{a}, \mathrm{b}}$ & $3.07 \pm 0.08$ & $0.33 \pm 0.31$ \\
\hline Unshod & Hind limb & $-0.097 \pm 0.012^{\mathrm{a}}$ & $122.3 \pm 12.7^{a}$ & $186.9 \pm 7.9$ & $2.98 \pm 0.03$ & $0.11 \pm 0.07$ \\
\hline Standard & Hind limb & $-0.098 \pm 0.012^{\mathrm{a}}$ & $152.2 \pm 14.1^{b}$ & $171.8 \pm 9.4$ & $2.80 \pm 0.05$ & $-0.21 \pm 0.19$ \\
\hline $\mathrm{HC}$ & Hind limb & $-0.101 \pm 0.012^{\mathrm{a}, \mathrm{b}}$ & $139.1 \pm 13.4^{a, b}$ & $169.5 \pm 8.7$ & $3.10 \pm 0.05$ & $0.53 \pm 0.26$ \\
\hline LC & Hind limb & $-0.109 \pm 0.012^{b, c}$ & $146.9 \pm 13.0^{a, b}$ & $170.4 \pm 8.3$ & $2.98 \pm 0.08$ & $0.04 \pm 0.07$ \\
\hline TLTC & Hind limb & $-0.113 \pm 0.012^{c}$ & $146 . \mid \pm 13.3^{\mathrm{a}, \mathrm{b}}$ & $171.1 \pm 8.6$ & $2.94 \pm 0.10$ & $-0.06 \pm 0.09$ \\
\hline PSC & Hind limb & $-0.127 \pm 0.012^{d}$ & $145.6 \pm 13 .\left.\right|^{a, b}$ & $166 \pm 8.3$ & $3.07 \pm 0.08$ & $0.33 \pm 0.31$ \\
\hline
\end{tabular}

For all variables, values were first determined when horses were unshod. Then, each horse was shod with each of the 5 shoe types (treatments) in a randomized order with approximately 22 hours between treatments.

${ }^{a-d}$ Within a column and limb, values with different superscript letters differ significantly $(P \leq 0.05)$; the absence of superscript letters indicates that the values did not differ significantly.
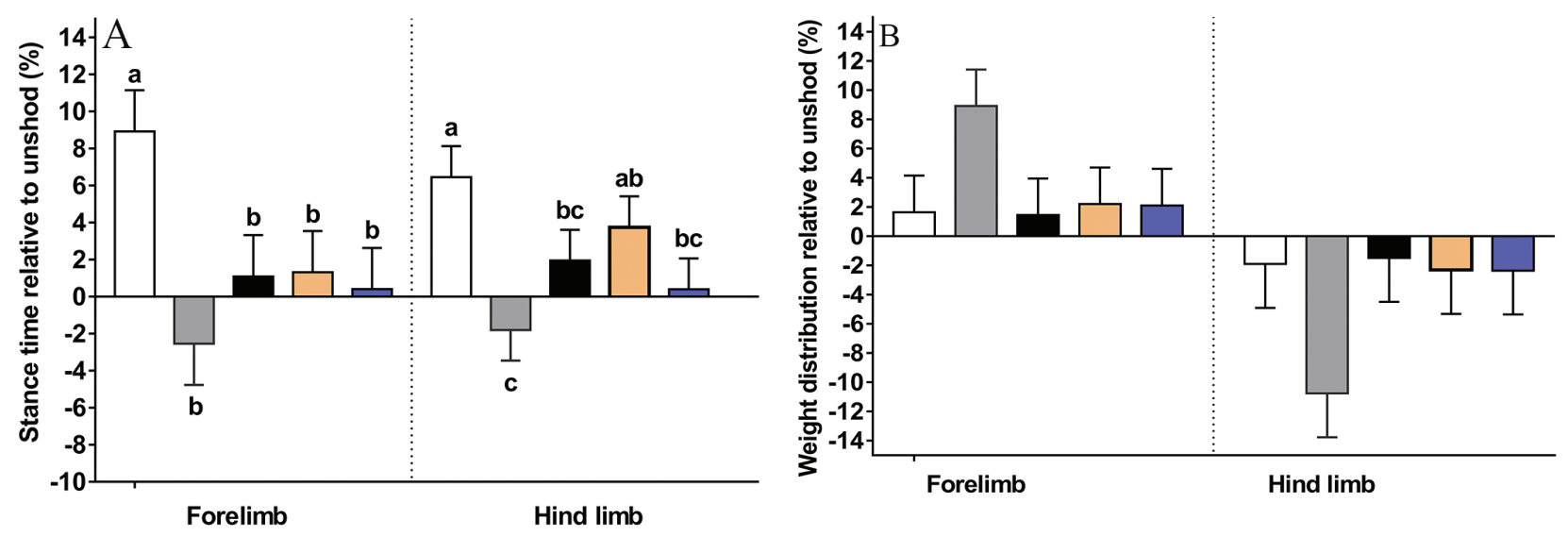

Figure 3-Least squares mean \pm SEM percentage change in the forelimb and hind limb stance time $(A)$ and weight distribution (B) for the 5 horses and 5 horseshoe treatments described in Figure 2 relative to when the horses were unshod. See Figure 2 for remainder of key. 
when the horses were unshod. However, we rejected our hypothesis that the $\mathrm{PVF}_{Z}$ would increase similarly for all shoe types because the mean percentage of change in forelimb $\mathrm{PVF}_{\mathrm{Z}}$ for the PSC shoes was significantly greater than that for each of the other 4 shoe types assessed, and the mean change in hind limb $\mathrm{PVF}_{\mathrm{Z}}$ was only increased from the unshod state (control) and did not differ significantly among the 5 shoe types. As expected, the PBF when horses were shod was greater than the PBF when horses were unshod in both the forelimbs and hind limbs. Compared with the control, the mean percentage increase in PBF was greatest for the PSC shoes and lowest for the $\mathrm{HC}$ shoes. The mean percentage increase in hind limb PBF did not differ significantly between the LC and TLTC shoes or between the standard and HC shoes, but the mean percentage increase in hind limb PBF for the LC and TLTC shoes was significantly greater than that for the standard and HC shoes. Given that the LC shoes increased the hind limb PBF from the control treatment to a greater extent than did the standard shoes, we rejected our hypothesis that the percentage increase in PBF would be greater when horses were shod with TLTC, PSC, and standard shoes, compared with when horses were shod with LC and HC shoes (ie, shoes with calks). Additionally, because the percentage increase in forelimb PBF from the control did not differ significantly among the 5 shoe types, we rejected our hypothesis that the $\mathrm{PBF}$ would be greater when horses were shod with LC shoes than when horses were shod with HC shoes. On the basis of the COF data observed during the present study, PSC and TLTC shoes provided the greatest traction and standard shoes provided the least traction for the hind limbs when horses were trotting on a paved surface. We believe that PSC and TLTC shoes are less likely to damage pavement surface than are shoes with calks (ie, HC and LC shoes) owing to the greater area of contact between the horseshoe and pavement surface. Collectively, these results suggested that PSC and TLTC shoes may enhance hoof protection and traction without altering the body weight distribution of horses when trotting on paved or solid stonelike surfaces.

The fact that the $\mathrm{PVF}_{Z}$ was greater when horses were shod than when horses were unshod in the present study was consistent with the long-established knowledge that horseshoes protect the hoof tissues of horses. ${ }^{24,36}$ Ground reaction forces generated when the hoof impacts the ground are absorbed by tissue deformation as they propagate up the limb. ${ }^{37,38}$ In a study ${ }^{2}$ of nonlame warmblood horses that were trotted on an asphalt surface, vertical deceleration forces were lower when horses were shod with polyurethane shoes than when unshod or shod with steel shoes. Consequently, the authors of that study ${ }^{2}$ suggested that polyurethane shoes could be used to decrease signs of joint pain in horses with osteoarthritis because they reduce the impact acceleration in the limbs when the hooves impact the ground. Although the PSC shoes evaluated in the present study differed from the polyurethane shoes evaluated in that other study, ${ }^{2}$ the plastic component still yielded greater deformation, compared with all iron shoes, which likely reduced the vertical impact forces propagated through the limb when the hoof struck the ground, resulting in less discomfort and a higher $\mathrm{PVF}_{\mathrm{Z}}$. The use of PSC shoes for horses traversing hard surfaces might decrease mechanical stresses on the distal aspects of the limbs and mitigate the associated risk of injury. ${ }^{39}$ In the present study, the changes in the GRFs observed when horses were shod versus unshod were greater in the forelimbs than in the hind limbs. That finding was most likely associated with the fact that, in nonlame horses, the forelimbs and hind limbs bear $60 \%$ and $40 \%$ of the animal's body weight, respectively; thus, the vertical impact is greater in the forelimbs than in the hind limbs, and changes in GRFs should be more discernable in the forelimbs. ${ }^{40,41}$

For the horses of the present study, the greatest change in $\mathrm{IMP}_{\mathrm{Z}}$ from the unshod state in both the forelimbs and hind limbs was observed when horses were shod with standard shoes. That finding was attributed to an increase in stance time when horses were shod with standard shoes because the velocity was consistent among trials for all shoe types, and velocity is negatively correlated with stance time. ${ }^{42,43}$ The differences observed among the braking timeto-propulsion time ratios for the 6 treatments were primarily dependent on changes in braking time in the forelimbs, whereas the changes in braking time and propulsion time were more evenly distributed, although propulsion time was usually slightly greater than braking time, in the hind limbs. That finding was consistent with the braking function of the forelimbs and propulsion function of the hind limbs. ${ }^{44}$ In both the forelimbs and hind limbs, the mean braking time was greatest when horses were shod with standard shoes, which probably contributed to the long mean stance time for that shoe type. The reason braking time was longer when horses were shod with standard shoes than when shod with the other types of shoes might have been a function of slipping, which typically occurs during braking as the hoof impacts the ground. ${ }^{21}$ In another study, ${ }^{10}$ the hoof slip distance when horses were cantering on a grassy surface was greater when they were shod with steel shoes than when they were shod with steel shoes with studs, and the slip distance was greatest for the hind limbs. Although differences in experimental design preclude direct comparisons between that study ${ }^{10}$ and the present study, the results of the present study suggested that hoof slippage was greater when horses were shod with standard shoes than when shod with the other 4 shoe types. Further investigation with kinematic equipment is necessary to elucidate the effect of horseshoe type on hoof slippage. ${ }^{10,21}$

Horseshoe material and road surface roughness and contact area affect friction. ${ }^{21,28}$ As previously mentioned, traction is a function of both PBF 
and $\mathrm{COF}^{21}$ Malleable and porous materials increase friction and, in the case of horseshoes, friction is increased even more by the presence of treads. ${ }^{45,46}$ Among the 6 treatments evaluated in the present study, traction was greatest for the PSC shoe and lowest when horses were unshod. That finding was in contrast to results of an in vitro study ${ }^{47}$ in which the kinetic COF between the hooves of cadaveric equine limbs and a concrete surface was greater when the hooves were unshod, compared to when the hooves were shod with iron shoes. The inherent differences between in vitro and in vivo studies are likely responsible for the apparently conflicting results between that study ${ }^{47}$ and the present study. The findings of the present study also contrast with the results of another study ${ }^{21}$ in which nonlame horses were trotted across a concrete surface when the forelimbs were shod with steel, rubber, or plastic shoes and the hind limbs were shod with steel shoes. In that study, ${ }^{21}$ the mean forelimb braking force and COF were lower when the limbs were shod with plastic shoes versus rubber or steel shoes. The plastic shoes evaluated in that study ${ }^{21}$ were different from the PSC shoes evaluated in the present study. In fact, on the basis of the provided descriptions, the PSC shoes evaluated in the present study were more similar to the rubber shoes evaluated in that other study. ${ }^{21}$

Among the 4 types of iron horseshoes evaluated in the present study, the TLTC shoes yielded the greatest mean percentage increase in hind limb PBF relative to the control and second greatest hind limb COF likely owing to the friction resulting from the large contact surface area $\left(5,200\right.$ to $\left.6,000 \mathrm{~mm}^{2}\right)$ of those shoes. Comparisons of GRFs between the LC and HC shoes were as expected given the larger contact surface of the LC shoes. The calks on the HC shoes more closely resembled studs than did the calks on the LC shoes, and HC shoes may be more appropriate for horses that spend a proportionately greater amount of time on penetrable surfaces versus nonpenetrable surfaces. ${ }^{10,24,48}$ In the present study, the mean percentage increase in hind limb PBF and mean hind limb COF were least when horses were shod with standard shoes than when shod with LC shoes, likely owing to slipping of the hind limbs when shod with standard shoes. It appeared that the friction generated by the somewhat granular surface of the calks on the LC shoes was greater than that generated by the standard shoes, despite the fact that the contact surface area for the LC shoes (range, 1,600 to 1,800 $\mathrm{mm}^{2}$ ) was substantially less than that for the standard shoes (range, 5,200 to $6,000 \mathrm{~mm}^{2}$ ).

For the 5 types of horseshoes evaluated in the present study, the mean percentage increase in PBF relative to the control differed significantly in the hind limbs but not the forelimbs, even though the forelimbs bore a greater proportion of the animal's body weight and associated forces and had a greater role in braking than did the hind limbs. ${ }^{44}$ The hind limbs of horses generally have a greater horizon- tal velocity and deceleration than the forelimbs, ${ }^{49}$ so changes in traction may be more evident in the hind limbs. Regardless, the results of the present study confirmed the importance of traction in both the forelimbs and hind limbs of horses. In the present study, kinetic measures were obtained when all 4 feet of each horse were shod with the same type of shoe. Further research is warranted to compare kinetic measures when horses are shod with different types of shoes on the forelimbs and hind limbs.

A limitation of the present study was the fact that only 5 horses of 2 light horse breeds (American Quarter Horse and Tennessee Walking Horse) were evaluated. The study had a crossover design. This design helped reduce the inherent variability in the study because each horse served as its own control, which was important because 1 gaited-breed horse was evaluated. Additional studies involving a diverse population of horses, including warmblood and draft horses, are necessary to augment and potentially validate the findings of this study. The color and texture of the force platform were similar to the concrete runway, but differences in stiffness between the 2 surfaces can affect GRFs, which is an inherent limitation of kinetic studies. ${ }^{24,50}$ Additionally, the results of the present study are specific to the concrete surface on which the kinetic tests were performed. Paved surfaces have varying characteristics, which may affect kinetic measures. ${ }^{21}$ Finally, pavement damage was not assessed in the present study; therefore, we could only speculate about the potential pavement damage induced by the different types of horseshoes.

Results of the present study indicated that, among the 5 types of horseshoes evaluated (HC, LC, TLTC, PSC, and standard shoes), traction for nonlame lightbreed horses trotting across a paved surface was best enhanced by the PSC and TLTC shoes. The horseshoe modifications assessed in this study did not alter body weight distribution among the 4 limbs. Thus, PSC and TLTC shoes may be the best options for hoof protection and traction in horses that spend a large amount of time traversing paved surfaces. The findings of the present study provided novel information regarding the effects of various horseshoe modifications for traction enhancement on the gait kinetics of horses. This information can be used to guide horseshoe designs to enhance safety for horses and the people around them.

\section{Acknowledgments}

Supported in part by the Tynewald Foundation, Federal Highway Administration, and Ohio Department of Transportation.

The authors thank Dr. Chin-Chi Liu for assistance with statistical analysis and Qingqiu Yang for assistance with data collection.

\section{Footnotes}

a. G*Power, version 3, Heinrich-Heine-Universität Düsseldorf, Düsseldorf, Germany.

b. Strategy, Purina Animal Nutrition LLC, Shoreview, Minn

c. Front unclipped standard shoe, Stockhoff's Horseshoes and Supplies, La Grange, Ky. 
d. Duplo composite horseshoes, MT EquiSports LLC, Big Timber, Mont.

e. E-slim nail, Delta Mustad Hoofcare Center Inc, Forest Lake, Minn.

f. Advanced Mechanical Technology Inc, Watertown, Mass

g. Mek 92-PAD, Joslyn Clark Controls Inc, Elizabethtown, NC.

h. Acquire V7.3, Sharon Software Inc, Watertown, Mass.

i. MWI Veterinary Supply Co, Boise, Idaho.

j. Zoetis Inc, Parsippany, NJ.

k. Polydoros LX model, Siemens, Munich, Germany.

1. FB1100, Fairbanks Scales Inc, Kansas City, Mo.

m. Prism, version 7, GraphPad Software Inc, San Diego, Calif.

n. JMP, version 14, SAS Institute Inc, Cary, NC.

\section{References}

1. Stutz JC, Vidondo B, Ramseyer A, et al. Effect of three types of horseshoes and unshod feet on selected non-podal forelimb kinematic variables measured by an extremity mounted inertial measurement unit sensor system in sound horses at the trot under conditions of treadmill and soft geotextile surface exercise. Vet Rec Open 2018;5:e000237.

2. Back W, van Schie MHM, Pol JN. Synthetic shoes attenuate hoof impact in the trotting warmblood horse. Equine Comp Exerc Physiol 2007;3:143-151.

3. Moore LV, Zsoldos RR, Licka TF. Trot accelerations of equine front and hind hooves shod with polyurethane composite shoes and steel shoes on asphalt. Animals (Basel) 2019;9:1119.

4. Kane AJ, Stover SM, Gardner IA, et al. Postmortem evaluation of homotypic variation in shoe characteristics of 201 Thoroughbred racehorses. Am J Vet Res 1996;57:1141-1146.

5. Nazzal MD, Holcombe E. Evaluation of partial depth pavement repairs on routes heavily traveled by Amish horse and buggies. Phase 1 final report. 2017. Available at: rosap.ntl.bts. gov/view/dot/32017/dot_32017_DS1.pdf? Accessed Oct 28, 2020.

6. Upjohn MM, Shipton K, Pfeiffer DU, et al. Cross-sectional survey of owner knowledge and husbandry practices, tack and health issues affecting working horses in Lesotho. Equine Vet J 2012;44:310-318.

7. Newsome D, Smith A, Moore SA. Horse riding in protected areas: a critical review and implications for research and management. Curr Issues Tour 2008;11:144-166.

8. Balch OK, Helman RG, Collier MA. Underrun heels and toe grab length as possible risk factors for catastrophic musculoskeletal injuries in Oklahoma racehorses, in Proceedings. 47th Am Assoc Equine Pract 2001;47:334-338

9. Hagen J, Hüppler M, Geiger SM, et al. Modifying the height of horseshoes: effects of wedge shoes, studs, and rocker shoes on the phalangeal alignment, pressure distribution, and hoofground contact during motion. J Equine Vet Sci 2017;53:8-18.

10. Harvey AM, Williams SB, Singer ER. The effect of lateral heel studs on the kinematics of the equine digit while cantering on grass. Vet J 2012;192:217-221.

11. Mahaffey CA, Peterson ML, Thomason JJ, et al. Dynamic testing of horseshoe designs at impact on synthetic and dirt Thoroughbred racetrack materials. Equine Vet J 2016;48:97102.

12. Sun J, Zhao J, Huang $Z$, et al. A review on binderless tungsten carbide: development and application. Nano-Micro Lett 2019;12:13

13. Stoffels SM, Bitonti TA, Gleason GL, et al. Mitigation of horseshoe damage to pavements. University Park, Pa: Pennsylvania State University, 1995.

14. Amitrano FN, Gutierrez-Nibeyro SD, Schaeffer DJ. Effect of hoof boots and toe-extension shoes on the forelimb kinetics of horses during walking. Am J Vet Res 2016;77:527-533.

15. Thomason JJ, Peterson ML. Biomechanical and mechanical investigations of the hoof-track interface in racing horses. Vet Clin North Am Equine Pract 2008;24:53-77.

16. Rogers $\mathrm{CW}$, Back W. Wedge and eggbar shoes change the pressure distribution under the hoof of the forelimb in the square standing horse. J Equine Vet Sci 2003;23:306-309.
17. Merkens HW, Schamhardt HC. Distribution of ground reaction forces of the concurrently loaded limbs of the Dutch Warmblood horse at the normal walk. Equine Vet J 1988;20:209-213

18. Witte TH, Knill K, Wilson AM. Determination of peak vertical ground reaction force from duty factor in the horse (Equus caballus). J Exp Biol 2004;207:3639-3648.

19. Bell RP, Reed SK, Schoonover MJ, et al. Associations of force plate and body-mounted inertial sensor measurements for identification of hind limb lameness in horses. Am J Vet Res 2016;77:337-345

20. Clayton HM, Lanovaz JL, Schamhardt HC, et al. The effects of a rider's mass on ground reaction forces and fetlock kinematics at the trot. Equine Vet J Suppl 1999;30:218-221.

21. Pardoe $\mathrm{CH}, \mathrm{McGuigan} \mathrm{MP}$, Rogers KM, et al. The effect of shoe material on the kinetics and kinematics of foot slip at impact on concrete. Equine Vet J Suppl 2001;33:70-73.

22. Bird JO, Chivers PJ. Friction. In: Bird JO, Chivers PJ, eds. Newnes engineering and physical science pocket book. Oxford, England: Newnes, 1993;235-237.

23. Zhang $\mathrm{H}$. Surface characterization techniques for polyurethane biomaterials. In: Cooper SL, Guan J, eds. Advances in polyurethane biomaterials. Cambridge, Mass: Woodhead Publishing, 2016;23-73.

24. Parkes RSV, Witte TH. The foot-surface interaction and its impact on musculoskeletal adaptation and injury risk in the horse. Equine Vet J 2015;47:519-525.

25. Blanchette MG, Powers CM. The influence of footwear tread groove parameters on available friction. Appl Ergon 2015;50:237-241.

26. Li KW, Chen CJ. The effect of shoe soling tread groove width on the coefficient of friction with different sole materials, floors, and contaminants. Appl Ergon 2004;35:499-507.

27. Moghaddam SRM, Acharya A, Redfern MS, et al. Predictive multiscale computational model of shoe-floor coefficient of friction. J Biomech 2018;66:145-152.

28. Manning DP, Jones C, Rowland FJ, et al. The surface roughness of a rubber soling material determines the coefficient of friction on water-lubricated surfaces. J Safety Res 1998;29:275-283

29. Kane AJ, Stover SM, Gardner IA, et al. Horseshoe characteristics as possible risk factors for fatal musculoskeletal injury of Thoroughbred racehorses. Am J Vet Res 1996;57:1147-1152.

30. Ura D, Carré M, Dominguez-Caballero JA. Tennis shoe-court interactions: examining relationships between contact area, pressure and available friction. Footwear Sci 2015;7(suppl 1):S87-S89.

31. Derler S, Kausch F, Huber R. Analysis of factors influencing the friction coefficients of shoe sole materials. Saf Sci 2008;46:822-832.

32. Persson BNJ, Tartaglino U, Albohr O, et al. Rubber friction on wet and dry road surfaces: the sealing effect. Phys Rev B 2005;71:035428.

33. Mirza MH, Bommala P, Richbourg HA, et al. Gait changes vary among horses with naturally occurring osteoarthritis following intra-articular administration of autologous platelet-rich plasma. Front Vet Sci 2016;3:29.

34. Taguchi T, Koh R, Takawira C, et al. Agmatine for pain management in dogs with coxofemoral joint osteoarthritis: a pilot study. Front Vet Sci 2018;5:311.

35. Lopez MJ, Quinn MM, Markel MD. Evaluation of gait kinetics in puppies with coxofemoral joint laxity. Am J Vet Res 2006;67:236-241.

36. Wilson A, Weller R. The biomechanics of the equine limb and its effect on lameness. In: Ross MW, Dyson SJ, eds. Diagnosis and management of lameness in the borse. $2 \mathrm{nd} \mathrm{ed}$. St Louis: Elsevier Saunders, 2011;270-281.

37. Spaak B, van Heel MCV, Back W. Toe modifications in hind feet shoes optimise hoof-unrollment in sound Warmblood horses at trot. Equine Vet J 2013;45:485-489.

38. Kawcak CE. Biomechanics in joints. In: McIlwraith $\mathrm{CW}$, Frisbie DD, Kawcak CE, et al, eds. Joint disease in the borse. 2nd ed. St Louis: Elsevier, 2016;25-32.

39. Oosterlinck M, Royaux E, Back W, et al. A preliminary 
study on pressure-plate evaluation of forelimb toe-heel and mediolateral hoof balance on a hard vs. a soft surface in sound ponies at the walk and trot. Equine Vet J 2014;46:751-755.

40. Stachurska A, Kolstrung R, Pieta M, et al. Differentiation between fore and hind hoof dimensions in the horse (Equus caballus). Arch Anim Breed 2008;51:531-540.

41. Back W, Schamhardt HC, Hartman W, et al. Kinematic differences between the distal portions of the forelimbs and hind limbs of horses at the trot. Am J Vet Res 1995;56:1522-1528.

42. Schilling BK, Falvo MJ, Chiu LZF. Force-velocity, impulsemomentum relationships: implications for efficacy of purposefully slow resistance training. J Sports Sci Med 2008;7:299-304.

43. McLaughlin RM Jr, Gaughan EM, Roush JK, et al. Effects of subject velocity on ground reaction force measurements and stance times in clinically normal horses at the walk and trot. Am J Vet Res 1996;57:7-11.

44. Clayton HM, Hobbs SJ. A review of biomechanical gait classification with reference to collected trot, passage and piaffe in dressage horses. Animals (Basel) 2019;9:763.
45. Mohamed MK, Samy A, Ali WY. Friction coefficient of rubber shoes sliding against ceramic flooring. KGK Rubberpoint 2012;65:52-57.

46. Ziaei M, Nabavi SH, Mokhtarinia HR, et al. The effect of shoe sole tread groove depth on the gait parameters during walking on dry and slippery surface. Int J Occup Environ Med 2013;4:27-35.

47. Vos NJ, Riemersma DJ. Determination of coefficient of friction between the equine foot and different ground surfaces: an in vitro study. Equine Comp Exerc Physiol 2006;3:191-198.

48. Kirk RF, Noble ISG, Mitchell T, et al. High-speed observations of football-boot-surface interactions of players in their natural environment. Sports Eng 2007;10:129-144.

49. Gustås P, Johnston C, Roepstorff L, et al. Relationships between fore- and hindlimb ground reaction force and hoof deceleration patterns in trotting horses. Equine Vet J 2004;36:737-742.

50. Burn JF, Usmar SJ. Hoof landing velocity is related to track surface properties in trotting horses. Equine Comp Exerc Physiol 2005;2:37-41.

\section{Appendix}

Description of the 5 horseshoe types or modifications intended to increase traction that were evaluated in a study conducted to assess the effects of each modification on the gait kinetics of nonlame horses during a trot on a concrete runway

\begin{tabular}{|c|c|c|c|c|c|}
\hline Horseshoe type & $\begin{array}{l}\text { Calks } \\
\text { (No.) }\end{array}$ & $\begin{array}{c}\text { Location } \\
\text { on horseshoe }\end{array}$ & Dimensions & $\begin{array}{l}\text { Contact surface area } \\
\left(\mathbf{m m}^{2}\right)\end{array}$ & Shoe weight (g) \\
\hline Standard & 0 & - & - & $5,200-6,000$ & $244-326$ \\
\hline $\mathrm{HC}$ & $\begin{array}{l}3 \\
2\end{array}$ & $\begin{array}{l}\text { Toe } \\
\text { I on each heel }\end{array}$ & $\begin{array}{l}\text { Height, } 10 \mathrm{~mm} \\
\text { Diameter, } 10 \mathrm{~mm} \\
\text { Height, } 10 \mathrm{~mm} \\
\text { Diameter, } 10 \mathrm{~mm}\end{array}$ & $250-393$ & $30 \mathrm{I}-387$ \\
\hline LC & I & $\begin{array}{l}\text { Toe } \\
\text { I on each heel }\end{array}$ & $\begin{array}{l}\text { Height, } 5 \mathrm{~mm} \\
\text { Length, } 40 \mathrm{~mm} \\
\text { Width, } 20 \mathrm{~mm} \\
\text { Height, } 5 \mathrm{~mm} \\
\text { Length, } 20 \mathrm{~mm} \\
\text { Width, } 20 \mathrm{~mm}\end{array}$ & $1,600-1,800$ & $365-451$ \\
\hline TLTC & 0 & - & - & $5,200-6,000$ & $244-330$ \\
\hline PSC & 0 & - & - & $8,000-10,750$ & $290-370$ \\
\hline
\end{tabular}

A commercially available iron horseshoe was used without modification (standard shoe) or served as the base for application of calks or a TLTC for the HC, LC, and TLTC shoes. Calks were composed of tungsten carbide and were forged onto the iron shoe. A TLTC was applied to the road surface side of the TLTC shoes. The PSC shoe was a commercially available horseshoe that was composed of a steel frame embedded in compressible plastic. The range was provided for contact surface area and weight of each horseshoe type because those 2 variables varied on the basis of shoe size, which varied among horses. Each shoe type (treatment) was applied to all 4 feet of 5 horses in a randomized order, with approximately 22 hours between treatments. Each horse underwent force platform testing for collection of kinetic gait data approximately 22 hours after each shoe application.

$-=$ Not applicable. 